CAKRAWALA - Repositori IMWI | Volume 4, Nomor 2, Oktober 2021

p-ISSN: 2620-8490; e-ISSN: 2620-8814

\title{
PENGARUH TAGLINE DAN BRAND AMBASSADOR TERHADAP BRAND AWARENESS KONSUMEN LAZADA DI KOTA SUKABUMI
}

\author{
Mariati Tirta Wiyata \\ Institut Manajemen Wiyata Indonesia \\ Email: mariatitirtawiyata@imwi.ac.id \\ Moch. Sopian Zaelani \\ Institut Manajemen Wiyata Indonesia \\ Email: sopianzaelani@gmail.com
}

\begin{abstract}
Abstrak
Penelitian ini bermaksud memahami dampak tagline dan brand ambassador terhadap brand awareness konsumen Lazada di Kota Sukabumi. Metodologi penelitian yang dipakai merupakan pendekatan kuantitatif dan teknik pengumpulan data memakai survei yang dibagi menjadi 100 responden. Pengujian kualitas instrumen dilakukan atas uji validitas dan uji reliabilitas. Hasil Penelitian ini menunjukan bahwa (1) Tagline secara parsial bedampak positif terhadap Brand Awareness (2) Brand Ambassador secara parsial bedampak positif terhadap Brand Awareness (3) Tagline dan Brand Ambassador secara simultan bedampak positif terhadap Brand Awareness.
\end{abstract}

Kata Kunci: tagline; brand ambassador; brand awareness

\section{Abstract}

This study aims to determine the effect of the tagline and brand ambassador on the brand awareness of Lazada consumers in Sukabumi City. The research methodology used is a quantitative approach and the data collection technique uses a survey which is divided into 100 respondents. Testing the quality of the instrument is carried out by testing the validity and testing the reliability. The results of this study indicate that (1) Tagline partially positive effect on Brand Awareness (2) Brand Ambassador partially positive effect on Brand Awareness (3) Tagline and Brand Ambassador simultaneously have a positive effect on Brand Awareness.

Keywords: tagline; brand ambassador; brand awarenes 


\section{Pendahuluan}

Digitalisasi didorong oleh pertumbuhan ekonomi Indonesia yang pesat pada tahun 2018 dan pertumbuhan teknologi Indonesia yang pesat sebesar 5,05\% . Menurut data (Statistik, 2018) Nielsen Research dan Bank Dunia, tren penetrasi seluler konsumen Indonesia akan mencapai 148 juta pengguna pada tahun 2021, pembelian online meningkat 42 juta, dan konsumen kelas menengah ke atas meningkat 128 juta. Pelanggan menjadi lebih mobile dan terus berpindah dari satu saluran offline ke saluran online (APJII, 2018).

Berdasarkan survei APJII (Asosiasi Penyelenggara Jasa Internet Indonesia) Pertumbuhan pengguna internet mengalami peningkatan yang sangat pesat pada tahun 2019 (Indonesia, 2018). Perkembangan teknologi memicu para pelaku bisnis memakai media ini guna mempertemukan penjual atas pembeli secara online yang bisa disebut jual beli online atau marketplace online. Atas banyaknya situs jual beli online ini, mengubah perilaku belanja konsumen khususnya mereka yang memakai dan memanfaatkan internet. Hal ini membuat konsumen tidak harus mendatangi pusat perbelanjaan (secara konvensional) melainkan cukup atas mengakses website atau situs perbelanjaan online tersedia di internet melalui gadget atau media elektronik lainya yang terhubung atas akses internet.

Indonesia merupakan pasar yang berkembang guna e-commerce. Penjualan Euromonitor Online di Indonesia telah mencapai \$1,1 miliar sejak 2014. Menurut (Badan Pusat Statistik, 2013), industri ecommerce Indonesia telah tumbuh atas total 26,2 juta pemain e-commerce dalam sepuluh tahun terakhir. Pengguna e-commerce pada
2019 diperkirakan mencapai 168,3 juta, serta mengalami peningkatan yang penting, peningkatan ini akan semakin bertumbuh seiring berkembangnya sektor UMKM (Usaha Mikro dan Menengah) di tanah air.

Kapasitas e-commerce Indonesia yang besar mempengaruhi cara orang berbelanja online, terutama kaum milenial. Riset dalam Indonesia Milenial Report 2019, milenial sebelum memutuskan guna membeli barang, mereka sangat senang atas perbandingan harga, kualitas produk, fitur dan promo atau diskon di beberapa ecommerce. Para millenial sangat suka dan senang merekomendasikan toko ecommerce langganan dan favorit mereka kepada teman-temannya (Utomo et al., 2019).

Keragaman merek menyebabkan terjadinya persaingan yang ketat dalam industri e-commerce. Supaya bisa bertahan dan berkembang dalam persaingan bisnis di waktu yang lama, berbagai strategi pemasaran dilakukan, perseroan lebih fokus pada produknya guna menarik perhatian konsumen (Oktaviani \& Lestari, 2019).

Kesadaran merek sangat penting dalam proses pemasaran. (Fahrurrazi et al., 2019) Brand awareness memperlihatkan kemampuan guna memahami atau mengingat produk yang diwakili oleh merek tersebut. Brand awareness membuktikan bahwa suatu merek akan selalu dikenali dan selalu diingat oleh para konsumen. Brand awareness ini akan mempengaruhi tingkat penjualan suatu produk (Aaker, 2018). Tingginya tingkat kesadaran pada suatu merek mampu menggambarkan tingginya keputusan pembelian produk. Oleh sebab itu, tingkat kesadaran yang tinggi terhadap sebuah merek mampu menentukan seberapa kuat perseroan mengembangkan dan bertahan dalam ketatnya persaingan. 
Faktor yang bedampak terhadap brand awareness antara lain merupakan tagline dan brand ambassador. Penelitian yang sebelumnya dilakukan oleh (Karim, 2019) memperlihatkan bahwa tangline dan brand ambassador berdampak positif terhadap kesadaran merek. Hal ini memperlihatkan bahwa branding dan brand ambassador mempengaruhi kesadaran merek lebih efektif dalam kegiatan promosi suatu merek.

Tagline disebut juga slogan merupakan deskripsi singkat yang merupakan bagian dari iklan yang dirancang supaya lebih mudah diingat orang. Tagline mempunyai peran penting. Tagline mampu berupa kalimat di akhir artikel yang merangkum tujuan tautan iklan (Handayani, 2018). Penggunaan tagline mampu menambah kemampuan dari iklan guna mencapai sasarannya yaitu atas memengaruhi yang menyaksikan supaya mempergunakan produk sebagaimana tertera di dalam iklan.

Selain memakai tagline dalam upaya pemasaran produk, perseroan juga memakai brand ambassador guna mengkomunikasikan pesan dari merek mereka. Brand ambassador merupakan istilah pemasaran yang dipakai pada orang yang mempromosikan produk atau layanan dalam bisnis yang disebut branding, serta berperan memberikan gambaran mengenai perseroan atas berpenampilan, bersikap, sesuai nilai dan etika perseroan. Menurut (Morrisan, 2015) brand ambassador merupakan pengiklan atau bintang iklan yang menunjang produk yang dipromosikan. Brand ambassador diperlukan diperlukan sebagai pembicara, agar merek mampu atas mudah diingat oleh konsumen, itulah sebabnya konsumen memutuskan guna memesan produk tersebut. Penggunaan selebritas sebagai brand ambassador mampu efektif guna meraih segmen pasar tertentu. Selebritas mampu berperan, berpenampilan, bersikap atas mewakili segmen pasar yang dituju.

Dalam dunia pemasaran saat ini, tidak cukup hanya menjalankan produk pada platform merek atau fondasi merek yang kuat, Tetapi juga tentang biaya dan nilai produk. Persaingan yang tinggi menuntut manajemen pemasaran guna menciptakan merek yang terdistribusi atas baik guna pasar sasaran (Aaker, 2018). Brand awareness mampu diartikan sebagai kemampuan guna memahami dan mengingat merek merupakan bagian dari produk tertentu.

Lazada salah satu marketplace yang memakai tagline dan brand ambassador dalam strategi periklanan guna membantu Lazada terhubung atas konsumen dan menarik pelanggan. Salah satu tagline Lazada yang sedang terkenal saat ini merupakan "Grand Year End Sale, Wujudkan Keinginanmu". Iklan tagline Lazada ditampilkan ditampilkan di media elektronik seperti TV dan di Instagram, Facebook, YouTube dan media online lainnya.

Lazada juga memberikan berbagai macam diskon besar besar pada top seller dan pada Lazmall. Melalui penawaran ini, konsumen mempunyai kesempatan guna mendapatkan produk yang ditargetkan berdasarkan kasus per kasus (Bagas, 2019). Lazada menyediakan berbagai macam produk antara lain elektronik, buku, mainan anak, kecantikan, rumah, olahraga, travel dan lainnya, semua atas mengunjungi website yang telah disediakan.

Menurut studi terbaru Google Temasek, penjualan e-commerce mencapai $\$ 10,9$ miliar pada tahun 2017. Jumlah ini meningkat tajam $41 \%$ dari $\$ 5,5$ miliar pada tahun 2015. Google juga mencatat bahwa 
minat konsumen terhadap e-commerce di Asia Tenggara berkembang pesat. Ini didasarkan pada volume pencarian ecommerce yang meningkat melebihi dua kali lipat dalam pencarian Google dalam dua tahun. Pada tahun 2017, terdapat beberapa perkembangan menarik terkait tumbuhnya ecommerce di Indonesia (DetikNet, 2017).

Menurut data dari peta e-commerce iPrice di Q1 2018, pengunjung Lazada mencapai 117,57 juta pengunjung, memungkinkan Lazada guna mempertahankan posisi terdepan sebagai pasar yang paling banyak dikunjungi. Sementara itu, Tokopedia menduduki peringkat kedua atas 117,3 juta pengunjung dari Januari hingga Maret tahun ini. Selanjutnya ada Bukalapak atas jumlah pengunjung 53,59 juta (iPrice, 2018).

Persaingan antar berbagai platform e-commerce di Indonesia pada penghujung tahun 2019 masih menarik perhatian. Pembiayaan baru dan kerjasama atas perseroan penyedia e-money menjadi topik hangat di industri akhir tahun. Promosi cashback dan obral akhir tahun yang menambah daya tarik belanja online. iPrice telah menerbitkan ulang Laporan Persaingan E-Commerce Indonesia guna Q1 2020. Ini mampu memberikan gambaran tentang dinamika industri e-commerce domestik. Rilis ini rutin dilakukan iPrice sejak tahun 2017 silam (Iprice, 2019).

\section{Tabel 1}

\section{Jumlah Pengunjung E-Commerce di}

\section{Indonesia}
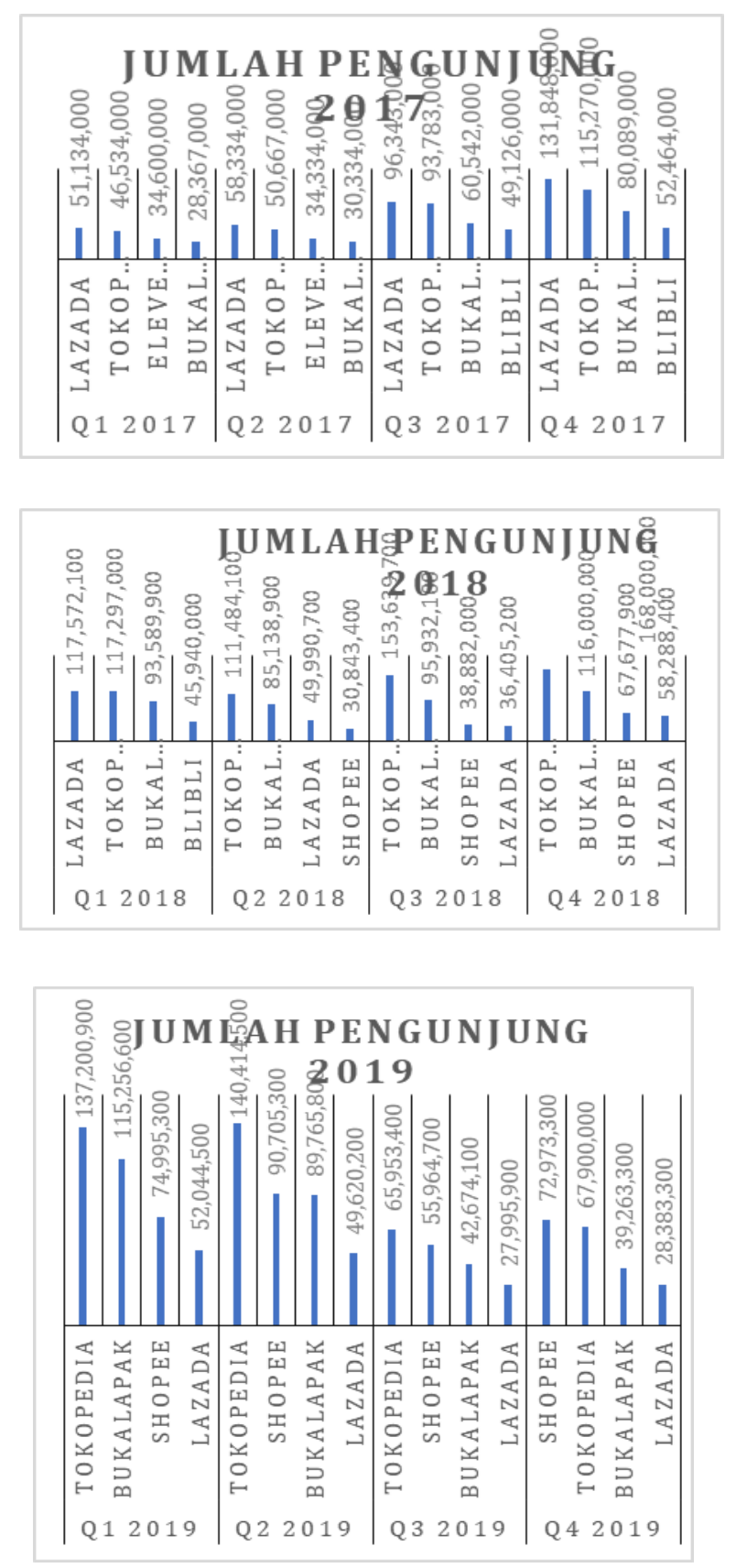


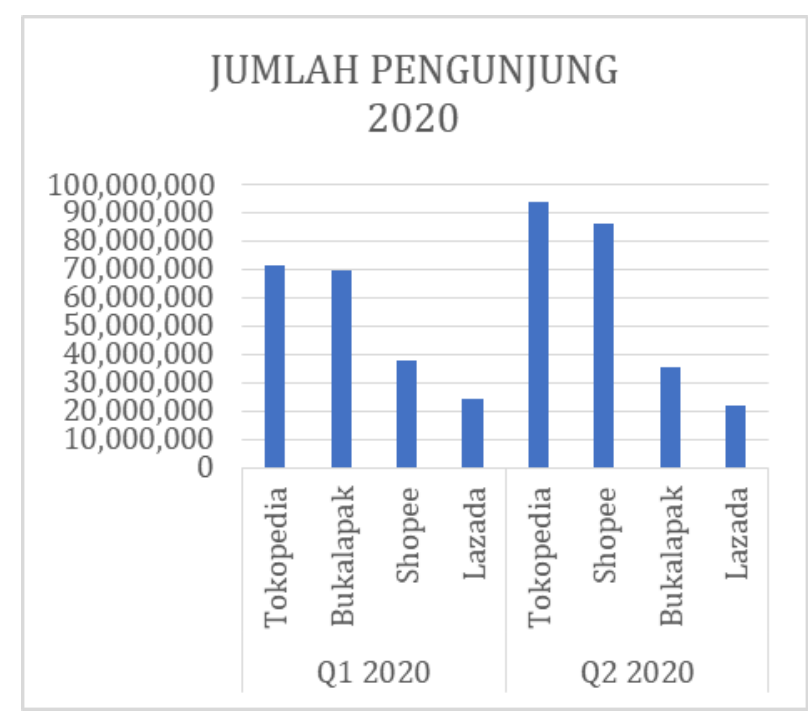

Sumber: iPrice.co.id

Lazada dalam beberapa Quartal pada Q1 sampai Q4 2017 dan Q1 pada 2018 selalu menduduki peringkat pertama dalam pencarian E-Commerce, akan tetapi pada Q2 2018 mulai menurun drastis menjadi peringkat ke 3, sampai saat ini Lazada ada pada peringkat ke 4 guna pencarian ecommerce di Indonesia dan guna jumlah pengunjungnya dari Q2 2018 Sampai saat ini Lazada selalu mengalami penurunan yang diduga karena masalah Tagline dan Brand Ambassador. Penelitian ini bermaksud memahami dampak tagline dan brand ambassador terhadap brand awareness pada konsumen Lazada di Kota Sukabumi.

\section{Metode Penelitian}

Penelitian ini dirancang atas metode kuantitatif deskriptif penelitian deskriptif menurut (Sugiyono, 2017) merupakan suatu penelitian yang dipakai dalam mencari tahu suatu variabel, yang mampu berupa satu atau lebih dari satu variabel, atas tidak membandingkan atau menghubungkan suatu variabel atas lainnya. Penelitian deskriptif melibatkan penyelidikan dan pencarian fakta dari berbagai isu. Penelitian ini bermaksud guna mengidentifikasi dan menganalisis dampak tagline dan brand ambassador 1 terhadap brand awareness pada pelanggan Lazada di Kota Sukabumi.

Penelitian ini melibatkan mahasiswa di Kota Sukabumi sebagai populasinya, peneliti membatasi populasi ini di 4 (empat) Perguruan Tinggi yaitu Institut Manajemen Wiyata Indonesia, Universitas Muhammadiyah Sukabumi, STIE PGRI Sukabumi, dan Universitas Nusa Putra. Purposive sampling merupakan teknik pengambilan sampel yang dipakai pada penelitian ini. Penelitian ini dilakukan pada pelanggan Lazada di Kota Sukabumi. Alasan memilih kota tersebut informan mendapatkan data bahwa terdapat kesenjangan.

\section{Hasil Penelitian dan Pembahasan \\ Uji Regresi Linear Berganda}

Hasil output pada tabel 2 memperoleh persamaan regresi berganda sebagai berikut:

1) $\beta 1=$ koefisien regresi Tagline (X1) 0,317 . Artinya jika ditambahkan satu unit pada tagline, sedangkan brand ambassador masih labil maka brand awareness akan meningkat sebesar $0,317 \%$.

2) $\beta 2=$ koefisien regresi Brand Ambassador (X2) 0.442. Artinya jika Brand Ambassador mengalami kenaikan satuan, tetapi variabel Tagline tetap, maka Brand Awareness mengalami peningkatan sebesar $0.442 \%$.

3) $\alpha=$ konstanta (nilai mutlak Y) jika semua variabel bebas $=0$ maka Brand Awareness akan menurun sebesar $11.951 \%$.

Tabel 2

Hasil Analisis Linear Berganda

Model Unstandardized Standardized Coefficients Coefficients t Sig. B Std. Error Beta

$\begin{array}{llllll}\text { (Constant) } & 11.951 & 2.098 & 5.696 & .000\end{array}$


p-ISSN: 2620-8490; e-ISSN: 2620-8814

\begin{tabular}{llllll}
\hline Total_X1 & .317 & .090 & .272 & 3.532 & .001 \\
\hline Total_X2 & .442 & .060 & .572 & 7.419 & .000 \\
\hline \multicolumn{1}{l}{ Koefisien Determinasi } \\
Hasil pengujian koefisien determinasi atau r \\
square mampu dilihat pada tabel 3 sebagai \\
berikut:
\end{tabular}

\section{Tabel 3}

\section{Koefisien Determinasi}

\begin{tabular}{cccccc}
\hline & & \multicolumn{3}{c}{ Adjusted } & Std. Error of Durbin- \\
Model R & R Square R Square & the Estimate & Watson \\
\hline 1 & $.735^{\text {a }}$ & .540 & .531 & 3.279 & 1.764 \\
\hline
\end{tabular}

a. Predictors: (Constant), Total_X2, Total_X1

b. Dependent Variable: Total_Y

Hasil pengujian pada tabel 3 memperlihatkan korelasi berganda (R), koefisien (R Square), dan koefisiensi determinasi disesuaikan (Adjusted $R$ Square). maka diraih nilai koefisiensi korelasi berganda $(\mathrm{R})$ sebesar 0,735. Hal tersebut membuktikan bahwa variabel Tagline dan Brand Ambassador mempunyai hubungan yang kuat, nilai koefisien determinasinya (R Square) sebesar 0,540 serta nilai koefisien determinasi yang sudah sesuai (Adjusted R Square) sebesar 0,531. Hal tersebut memperlihatkan bahwa $53,1 \%$ dari perbedaan kesadaran produk mampu direpresentasikan sebagai variabel independen (tagline dan brand ambassador), sedangkan $46,9 \%$ sisanya tidak teridentifikasi dalam penelitian ini.

\section{Uji t (Uji Parsial)}

Uji-t dipakai guna menguji dampak Model Sum of Squares df Square F Sig.

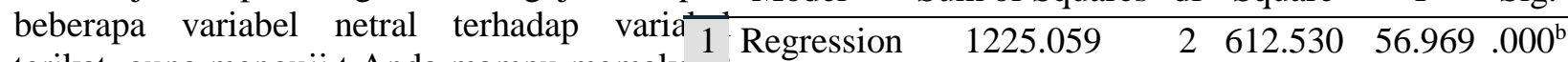
terikat. guna menguji t Anda mampu memaki (dua) sisi dan tingkat pentingsi 0,05 , der: kebebasan $(\mathrm{df})=\mathrm{n}-\mathrm{k}$. Uji $\mathrm{t}$ dilakukan membandingkan nilai $t$ hitung terh: Hasil pengujian terhadap $t$ statistic $n$

1) Jika sig $<\alpha$, thitung $>$ t tabel aan koerısien $\beta$ positif, maka hipotesis diterima.

2) Jika sig $<\alpha$, t hitung $<\mathrm{t}$ tabel dan koefisien $\beta$ negatif, maka hipotesis tidak diterima.

3) Jika sig $<\alpha$, t hitung $<\mathrm{t}$ tabel, maka hipotesis ditolak.

Output SPSS pada Tabel 2 memperlihatkan bahwa probabilitas 2 sisi dipakai guna menentukan nilai t-tabel, mencari distribusi t pada a $=5 \%: 2=2,5 \%$ (uji 2 sisi), derajat kebebasan $(\mathrm{df}=\mathrm{nk}$ atau $100-3=97(\mathrm{n}$ merupakan jumlah periode pengamatan, $\mathrm{k}$ merupakan jumlah variabel), atas memakai uji 2 sisi (pentingsi $=0,025$ ), diraih t-tabel sebesar 1,98472 .

a. Hasil Uji Hipotesis 1: dampak tagline terhadap kesadaran merek

Tabel 4.15 memperlihatkan bahwa tingkat pentingsi variabel Tagline merupakan 0,001 atau $<0,05$, dan nilai thitung 3,532>t-tabel 1,98472, memperlihatkan bahwa variabel bebas mempunyai dampak yang penting terhadap variabel terikat. Sehingga $\mathrm{H} 2$ diterima serta mampu disimpulkan bahwa variabel tagline mempunyai dampak penting pada Brand Awareness.

a. Hasil Uji Hipotesis 2: dampak Brand Ambassador terhadap Brand Awareness

Tabel 4.15 memuat hasil pengujian yang memperlihatkan bahwa gambar produk mempunyai tingkat pentingsi sebesar 0,000 atau $<0,05$ serta nilai $t$ hitung $=7,419>$ t-tabel 1,98472 . Artinya variabel bebas mempunyai dampak penting pada variabel terikat. Sehingga H1 diterima dan mampu disimpulkan bahwa variabel brand ambassador mempunyai dampak positif penting terhadap Brand Awareness.

\section{Uji F (Simultan)}

Jika sig $<0,05$ dan $\mathrm{f}$ hitung $>\mathrm{f}$ tabel, berarti semua variabel bebas bedampak penting terhadap variabel terikat secara bersamaan.

\section{Tabel 4}

\section{Hasil Uji F}

\section{Mean}

\begin{tabular}{crrr}
\hline Residual & 1042.941 & 97 & 10.752 \\
\hline Total & 2268.000 & 99 &
\end{tabular}

a. Dependent Variable: Total_Y

b. Predictors: (Constant), Total_X2, Total_X1

Sumber: Olah Data 2020

Seperti terlihat dari Tabel 4 uji f di atas, $\mathrm{f}$ hitung $=56,969 \mathrm{f}$ tabel $\mathrm{df} 1=\mathrm{k}-1$, df 2 $=\mathrm{n}-\mathrm{k}$. df $1=3-1=2$, df $2=100-3=97$, sehingga $F$ tabelnya merupakan 3,09. Terlihat $\mathrm{f}$ hitung > f tabel $(56,969>3,09)$, diraih nilai pentingsi $=0,000<0,05$. Maka mampu diambil kesimpulan bahwa tagline 
dan brand ambassador mempengaruhi kesadaran merek secara bersamaan.

Uji statistik $\mathrm{F}$ memperlihatkan nilai $\mathrm{F}$ hitung 56,969 > F tabel 3,09, serta taraf pentingsi $0,000<0,05$. Ha diterima karena tingkat pentingsinya $<0,05$, maka dikatakan tagline dan brand ambassador mempunyai dampak secara simultan (co) terhadap kesadaran merek.

\section{PEMBAHASAN}

\section{Pengaruh Tagline terhadap Brand} Awareness

Pengujian hipotesis uji $t$ memperlihatkan bahwa terdapat dampak persepsi tagline terhadap Brand Awareness. Setiap Tagline yang dipakai oleh perseroan pasti mempunyai arti dan nilai tersendiri bagi perseroan, termasuk akun-akun di Lazada. Atas adanya Tagline konsumen menyadari suatu produk dan tagline merupakan daya tarik yang unik guna menarik pengguna.

Perlu juga dicatat bahwa tagline yang baik mempunyai banyak indikator penting guna mendukungnya agar berhasil menjalankan fungsinya. (Mahisa et al., 2019) menyatakan keberhasilan tagline dalam memenuhi fungsinya mampu dilihat melalui tiga indikator. Indikator tersebut berupa Familiarity, Differentiation, and Message/Value. Hasil penelitian (Widyastuti \& Nugroho, 2019) memperlihatkan bahwa Tagline mempunyai efek positif dan penting terhadap Brand Awareness.

\section{Pengaruh Brand Ambassador terhadap Brand Awareness}

Hasil uji t variabel Brand Ambassador memperlihatkan bahwa tingkat pentingsi variabel Brand Awareness merupakan 0,000 atau $<0,05$, dan $\mathrm{t}$ hitung 7,419>t tabel 1,98472, memperlihatkan bahwa variabel bebas mempunyai dampak yang positif dan penting pada kesadaran Brand Awareness.

Brand Ambassador atau identitas yang berperan sebagai media pemasaran guna mewakili individualitas, martabat manusia, branding, serta pemasaran (Gita \& Setyorini, 2016). Brand Ambassador ini berperan sebagai daya dorong guna para konsumen dan memberikan testimonial terhadap produk itu sendiri, sehingga bisa menimbulkan kesadaran merek pada produk tersebut.

Penelitian serupa menyatakan bahwa Brand Awareness berefek positif dan penting terhadap Brand Awareness (Osak \& Pasharibu, 2020).

Tagline dan Brand Ambassador memengaruhi Brand Awareness

Uji statistik $\mathrm{F}$ memperlihatkan $\mathrm{F}$ hitung 56,969 > F tabel 3,09, serta pentingsinya sebesar $0,000<0,05$. Ha diterima karena tingkat pentingsinya $<0,05$, maka mampu dikatakan bahwa tagline dan brand ambassador mempunyai dampak secara simultan (co) terhadap kesadaran Brand awareness.

Brand awareness itu sendiri merupakan kemampuan mengidentifikasi atau mengingat merek yang termasuk dalam suatu kategori. Brand recall merupakan kemampuan pembeli dalam mengingat nama brand saat mencari produk tertentu (Aaker, 2018). Meningkatkan kesadaran konsumen merupakan tantangan bagi merek, dan keharusan bagi bisnis yaitu mempertahankan kesadaran merek.

Hasil penelitian lain (Karim, 2019) memperlihatkan bahwa tagline dan Brand Ambassador mempunyai dampak positif dan penting terhadap Brand Awareness.

\section{Simpulan}

Tagline secara parsial bedampak positif terhadap Brand Awareness pada konsumen Lazada Indonesia. Secara parsial Brand Ambassador bedampak positif terhadap Brand Awareness pada konsumen Lazada Indonesia. Secara simultan Tagline dan Brand Ambassador bedampak positif terhadap Brand Awareness konsumen Lazada Indonesia.

\section{Saran}

Saran merupakan usulan atas perbaikan dari penyelesaia masalah yang dihadapi dalam penelitian ini maupun ide usulan penelitian lanjutan atau revisiting 
penelitian yang sama atas sudut pandang yang beberda.

\section{Daftar Pustaka}

Aaker, D. A. (2018). Manajemen ekuitas merek.

APJII, D. P. (2018). Laporan Survey Penetrasi dan Profil Perilaku Pengguna Internet Indonesia. Jakarta: Asosiasi Penyelenggara Jasa Internet Indonesia.

Badan Pusat Statistik. (2013). Badan Pusat Statistik. https://www.bps.go.id/

Bagas, F. (2019). Lazada Promo GedeGedean di Harbolnas 12.12, Free Ongkir Pada 13 - 15 Desember. Nextren.

https://nextren.grid.id/read/011942965/1 azada-promo-gede-gedean-diharbolnas-1212-free-ongkir-pada-1315-desember?page $=$ all

DetikNet. (2017). Persaingan e-Commerce Indonesia di 2017, Siapa Terpopuler? DetikNet.

https://inet.detik.com/cyberlife/d3793019/persaingan-e-commerceindonesia-di-2017-siapa-terpopuler

Fahrurrazi, F., Khoirunnisa, S., \& Somantri, B. (2019). dampak Marketing Mix Terhadap Customer Loyalty Melalui Customer Satisfaction Kerudung di Outlet Rabbani. Cakrawala Repositori IMWI, 2(2), 26-39.

Gita, D., \& Setyorini, R. (2016). dampak Brand Ambassador Terhadap Brand Image Pada Perseroan Online Zalora. co. id. EProceedings of Management, $3(1)$.

Handayani, D. (2018). dampak Penggunaan Tagline "Tunjukkan Kulit Cerah Alamimu" Pada Iklan Clean \& Clear Natural Bright Face Wash Terhadap Keputusan Pembelian.

Indonesia, A. (2018). Penetrasi \& profil perilaku pengguna internet Indonesia.
APJII.[Google Scholar].

iPrice. (2018). Lazada, e-Commerce Paling Banyak Pengunjung TW I 2018. Databoks.Katadata.Co.Id.

https://databoks.katadata.co.id/datapubl ish/2018/04/18/lazada-e-commercepaling-banyak-pengunjung-tw-i-2018

Iprice. (2019). Peta Persaingan ECommerce Indonesia Q4 2018 - iPrice Group. Iprice.Co.Id. https://iprice.co.id/trend/insights/petapersaingan-e-commerce-indonesia-q42018-iprice-group/

Karim, A. (2019). dampak Tagline Iklan Versi "Axis Hits Bonus" Dan Brand Ambassador Terhadap Brand Awareness Kartu Axis (Studi Pada Mahasiswa STIE Amkop Makassar). Movere Journal, 1(1), 1-13.

Mahisa, R. K., Permadi, L. A., \& Darwini, S. (2019). Analisis dampak Tagline Dan Brand Ambassador Terhadap Brand Awareness Telepon Seluler Merek Oppo (Studi Pada Pekerja Kantoran Di Kota Mataram). Jurnal Riset Manajemen, 19(2), 86-97.

Morrisan, M. A. (2015). Periklanan komunikasi pemasaran terpadu. Kencana.

Oktaviani, P., \& Lestari, R. (2019). dampak Celebrity Endorser, Tagline dan Citra Merek Terhadap Kesadaran Merek Konsumen Facial Foam Pond's di SMK Al-Makmur Ciganjur Jakarta Selatan. Oikonomia: Jurnal Manajemen, 13(2).

Osak, D. J., \& Pasharibu, Y. (2020). dampak Brand Ambassador Dan Tagline Terhadap Keputusan Pembelian Online Dengan Mediasi Brand Awareness. EJurnal Ekonomi Dan Bisnis Universitas Udayana, 9, 357-380.

Statistik, B. P. (2018). Produk Domestik Bruto Indonesia Triwulanan. Jakarta: BPS. 
CAKRAWALA - Repositori IMWI | Volume 4, Nomor 2, Oktober 2021

p-ISSN: 2620-8490; e-ISSN: 2620-8814

Sugiyono. (2017). Metode Penelitian Kuantitatif, Kualitatif dan $R \& D$. Alfabeta.

Utomo, W. P., Lubis, U. Z., \& Sudradjat, S. A. (2019). Indonesia millennial report 2019. IDN Research Institute, 1, 61.
Widyastuti, D. A., \& Nugroho, M. R. (2019). Efektivitas Tagline\# DijaminOri terhadap Brand Awarness E-Commerce JD. ID. Journal of Entrepreneurship, Management and Industry (JEMI), 1(4), 211-225. 